\title{
Zinc Deficiency: Descriptive Epidemiology and Morbidity among Preschool Children in Peri-urban Population in Delhi, India
}

\author{
Usha Dhingra', Girish Hiremath', Venugopal P. Menon², Pratibha Dhingra², \\ Archana Sarkar ${ }^{2}$, and Sunil Sazawal ${ }^{1,2}$ \\ 'Department of International Health, Johns Hopkins Bloomberg School of Public Health, Baltimore, MD 2I205, USA and \\ ${ }^{2}$ Center for Micronutrient Research, Annamalai University, Annamalainagar 608002, Tamil Nadu, India
}

\begin{abstract}
Community-based data relating to factors influencing zinc deficiency among preschool children in India are inadequate. Data of a large, double-blinded, randomized, controlled zinc-supplementation trial were used for assessing the descriptive epidemiology of zinc deficiency among children aged 6-35 months $(\mathrm{n}=940)$. In total, 609 children were followed up for 120 days for information on morbidity. Of these children, 116 from the control group belonging to the upper and the lower $25^{\text {th }}$ quartile of plasma zinc status at baseline were selected for assessing the association of zinc deficiency with prospective morbidity. At baseline, demographic, socioeconomic and dietary information was collected, and anthropometric measurements and levels of plasma zinc were assessed. At baseline, $73.3 \%$ of the children were zinc-deficient (plasma zinc $<70 \mu \mathrm{g} / \mathrm{dL}$ ), of which $33.8 \%$ had levels of plasma zinc below $60 \mu \mathrm{g} / \mathrm{dL}$. A significantly higher risk of morbidity was prevalent among the subjects with lower plasma zinc compared to those with higher levels of plasma zinc.
\end{abstract}

Key words: Child; Diarrhoea; Double-blind method; Epidemiology, Descriptive; Morbidity; Randomized controlled trials; Slums; Zinc; Zinc deficiency; Zinc supplementation; India

\section{INTRODUCTION}

Zinc deficiency is an important cause of morbidity due to infectious diseases and growth-faltering among young children. Increased demand of zinc due to rapid growth and decreased intake of zinc due to inadequate feeding practices predispose preschool children, especially living in communities of low socioeconomic level at an elevated risk of zinc deficiency (1). Compelling evidence from intervention trials suggests that supplementation of zinc could reduce the risk of pneumonia and the risk and duration of diarrhoea, dysentery, and malaria among preschool children (2-5). However, little information is available on the global prevalence of zinc deficiency. On the other hand, the population/

Correspondence and reprint requests should be addressed to:

Dr. Sunil Sazawal

Department of International Health, W 5517

615 North Wolfe Street

Johns Hopkins Bloomberg School of Public Health

Baltimore, MD 21205

USA

Email: ssazawal@jhsph.edu

Fax: 410-955-2029 national-level zinc-supplementation programmes have achieved limited success in alleviating zinc deficiency worldwide (6). Lack of reliable methods to determine the levels of plasma zinc, paucity of knowledge of the socioeconomic, dietary and demographic factors influencing the distribution of zinc deficiency, and inadequate documentation of rates and causes of zinc deficiency among vulnerable preschool children and its impact on childhood morbidities among different populations are some most important limiting factors (7-8).

Traditionally, zinc deficiency at the population level has been estimated by the surrogate markers, such as total daily per-capita amount of zinc in the food-supply, compared to the likely zinc requirements, or by the rates of stunting among preschool children (9). Using the food balance-sheets, Wuehler et al. estimated that about $71.2 \%$ of the total population in southeast Asia was at risk of developing zinc deficiency (10). The prevalence of zinc deficiency among a population can be assessed by a combination of techniques, such as the prevalence of clinical outcomes of zinc deficiency (diarrhoea, pneumonia, stunting), assessment of intake of die- 
tary zinc, biochemical measures of zinc concentration, or assessment of functional outcomes of zinc supplementation (11). A community-based study conducted in the North-West Frontier province in Pakistan reported that one in two preschool children suffers from zinc deficiency (12). Zinc deficiency has been suspected to be prevalent among preschoolers in India due to high consumption of cereal-based weaning diets and high rates of recurrent infections. There is also limited systematically-collected information on the quantitative estimates of zinc deficiency, especially those living in communities of low socioeconomic level (13). Determining the magnitude of zinc deficiency and its association with risk of morbidities among preschool children in India can contribute to planning strategies to alleviate zinc deficiency and the related adverse health consequences.

In this study, we present the descriptive epidemiology of zinc deficiency and the associated risk of morbidity due to infectious diseases among preschool children in an urban slum in northern India.

\section{MATERIALS AND METHODS}

\section{Study subjects and sample}

The main study was a double-masked, randomized controlled zinc-supplementation trial carried out in an urban slum in New Delhi, and the details of the study population, design, methods, eligibility, recruitment, and randomization have earlier been reported (14-15). Briefly, 940 children aged 6-35 months and presenting to the community-based clinic with history of acute diarrhoea (defined as having passed at least four unformed stools in the past 24 hours and having diarrhoea for less than seven days) were enrolled and randomly allocated to either zinc group $(n=468)$ or control group $(\mathrm{n}=472)$. A randomization schedule with permuted blocks of fixed length (10 per block) was employed for randomization. At the first home-visit, after recovery from diarrhoeal episode at enrollment (passage of three or fewer stools for three consecutive days), 609 of these children were followed up for six months (long follow-up), and for the rest, the follow-up was terminated after recovery from diarrhoeal episode $(n=331)$. Home-visits daily for supplementation and every fifth day for the assessment of morbidity were made to evaluate preventive effects of zinc on diarrhoea, dysentery, and respiratory disease-related morbidity.

The prevalence and descriptive epidemiology of zinc deficiency were based on the baseline evaluation of the enrolled children $(n=940)$. Of the 609 children in the long follow-up, 116 allocated to the control group belonging to the upper and the lower $25^{\text {th }}$ quartile of baseline plasma zinc status were selected for evaluating the association of zinc deficiency with prospective morbidity. The prospective morbidity was assessed for a follow-up period of 120 days. For comparison of the prevalence of zinc deficiency among children with acute diarrhoea and those without diarrhoea, 193 children from the control group who did not have diarrhoea in the three days before the collection of blood samples after 120 days of supplementation (Fig. 1).

\section{Baseline information and follow-up}

At enrollment, a health worker collected socioeconomic and demographic data, information on the breastfeeding status, intake of non-breastmilk, frequency of consumption of zinc-rich foods (such as green-leafy vegetables, pulses, rice, wheat bread, fruits, meat, fish, eggs, chicken, butter, etc.) in the two weeks before enrollment and recorded anthropometric measurements. A research physician gathered a detailed morbidity history (information regarding the episodes and duration of diarrhoea, vomiting in the last 24 hours, pneumonia, and acute respiratory tract infections [ALRIs] in the last two months), and nutritional profile and conducted a thorough physical examination.

Blood sampling was done to assess the levels of plasma zinc at the baseline $(\mathrm{n}=940)$ and after 120 days of follow-up $(n=472)$. For the estimation of plasma zinc, venous blood sample was collected in a monovette trace element-free heparinized syringe; the plasma was separated within 15 minutes of collection of the samples and was transferred into trace element-free Eppendorf plastic tubes to be stored at $-20^{\circ} \mathrm{C}$. Plasma zinc was estimated using atomic absorption spectrophotometry following standard methods (16). C-reactive protein was also estimated on a Cobas Fara analyzer (Roche Products, Welwyn, United Kingdom).

Children were prospectively followed up by homevisits every fifth day by the health worker. Using the standard definitions of the World Health Organization, information was gathered on days of illness, days and episodes of diarrhoea, days of dysentery, days with ALRI, and episodes of pneumonia. In the case of any morbidity, the children were referred to the project physician for management.

\section{Statistical analysis}

For evaluating the prevalence of zinc deficiency among the study population, two cut-offs were used: plasma zinc $<60 \mu \mathrm{g} / \mathrm{dL}$ and plasma zinc 


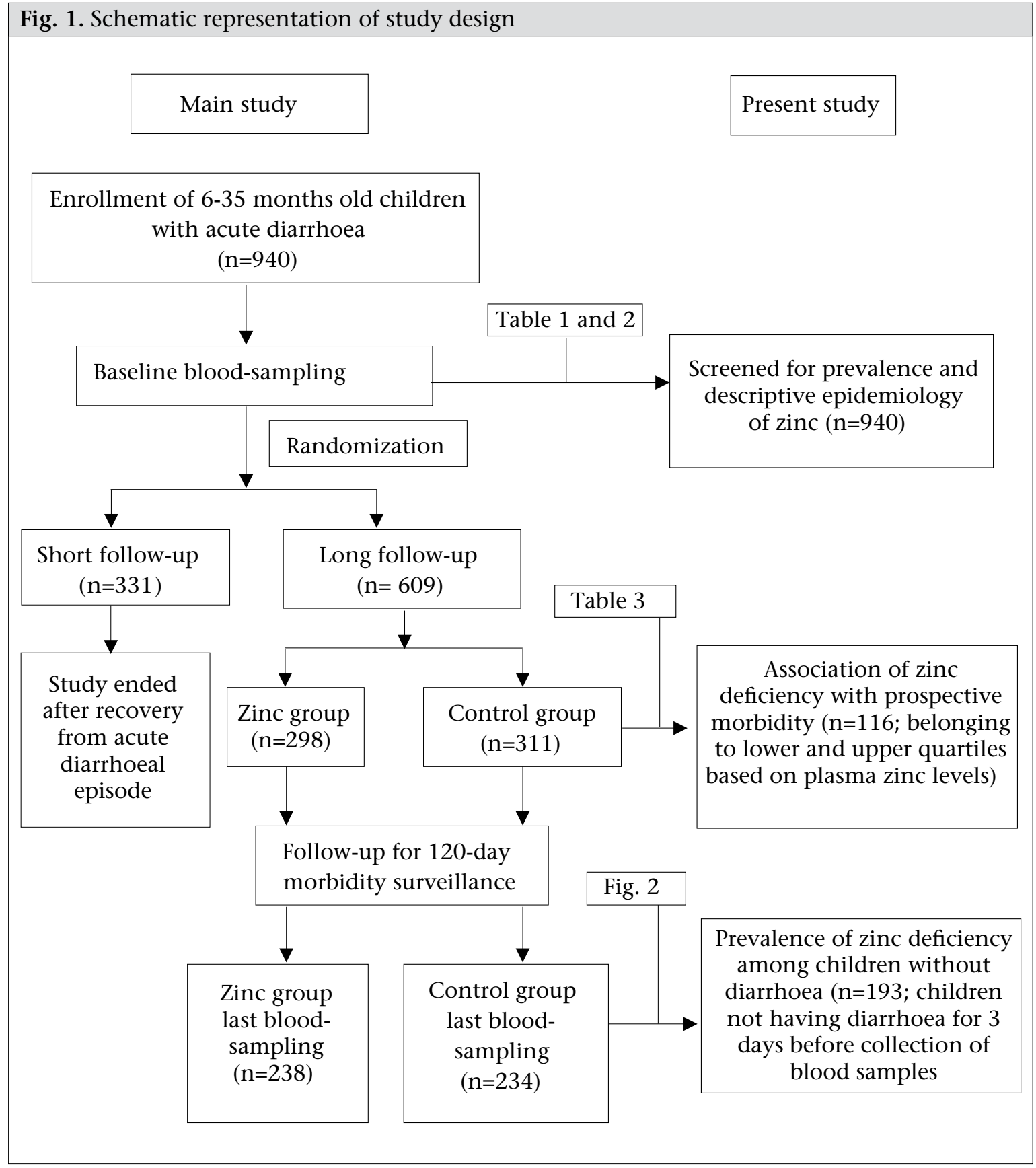

$<70 \mu \mathrm{g} / \mathrm{dL}$. To understand the descriptive epidemiology of zinc deficiency, we categorized the entire cohort of 940 children by baseline plasma zinc values into lower quartile (baseline plasma zinc values below $25^{\text {th }}$ percentile, i.e. plasma zinc $\leq 56.0 \mu \mathrm{g} / \mathrm{dL}$ ), middle quartile (baseline plasma zinc values $\geq 25^{\text {th }}$ percentile, and $\leq 75^{\text {th }}$ percentile, i.e. plasma zinc $>56.0$ to $\leq 70.0 \mu \mathrm{g} / \mathrm{dL}$ ), and upper quartile (baseline plasma zinc values $>75^{\text {th }}$ percentile, i.e. plasma zinc $>70.0 \mu \mathrm{g} / \mathrm{dL}$ ) and compared the baseline socioeconomic, demographic and dietary factors affecting the levels of plasma zinc among the quartiles. To evaluate the impact of baseline plasma zinc on prospective morbidities, the risk of morbidities was compared among the lower and upper quartile groups after adjusting for covariates, such as socioeconomic score, education of mothers/fathers, water supply, age and gender of the child. Persontime analysis was performed with actual follow-up as denominator. For the effect on the incidence of diarrhoea/dysentery, respiratory and other childhood illnesses, relative risk was estimated using Poisson regression. All statistical analyses were carried out using the SPSS software (version 12.0) (SPSS Inc., Chicago, Illinois, USA) and the Stata software (version 9.2) (Stata Corp., College Station, Texas, USA). 


\section{RESULTS}

Zinc deficiency as assessed by estimation of plasma zinc showed that $73.3 \%$ of the children were zincdeficient (plasma zinc $<70 \mu \mathrm{g} / \mathrm{dL}$ ), of whom $33.8 \%$ had levels of plasma zinc below $60 \mu \mathrm{g} / \mathrm{dL}$. Younger children were at a lower risk of zinc deficiency than were older children; however, the prevalence was similar among male and female children (Table 1). of plasma zinc and the risk of morbidities due to infectious diseases.

Recent studies, using data on food-availability, estimated that zinc deficiency affects about one-third of the world's population, with estimates ranging from $4 \%$ to $73 \%$ across subregions. Although severe zinc deficiency is rare, mild-to-moderate zinc deficiency is quite common throughout the world

\begin{tabular}{|c|c|c|c|c|}
\hline \multirow{2}{*}{ Variable } & \multicolumn{2}{|c|}{ Plasma zinc $<70 \mu \mathrm{g} / \mathrm{dL}$} & \multicolumn{2}{|c|}{ Plasma zinc $<60 \mu \mathrm{g} / \mathrm{dL}$} \\
\hline & No. & $\%$ & No. & $\%$ \\
\hline All children $(n=940)$ & 689 & 73.3 & 318 & 33.8 \\
\hline \multicolumn{5}{|l|}{ Age (months) } \\
\hline $5-11(n=383)$ & 257 & 67.1 & 112 & 29.2 \\
\hline $12-23(n=370)$ & 281 & 75.9 & 137 & 37.0 \\
\hline$\geq 24(\mathrm{n}=187)$ & 151 & 80.7 & 69 & 36.9 \\
\hline \multicolumn{5}{|l|}{ Gender } \\
\hline Male $(n=485)$ & 228 & 71.7 & 104 & 32.7 \\
\hline Female $(\mathrm{n}=455)$ & 228 & 78.4 & 119 & 40.9 \\
\hline
\end{tabular}

The descriptive epidemiology of zinc deficiency is presented in Table 2. The children in the cohort were categorized into three quartiles based on levels of baseline plasma zinc. The nutritional status, breastfeeding status, recent intake of dietary zincrich food(s), including the consumption of nonbreastmilk, and socioeconomic level among children were similar across the quartiles. Diarrhoeal and respiratory morbidity was similar among the quartiles. C-reactive protein was positive in only $0.1 \%$ of the children. The prevalence of zinc deficiency among children having acute diarrhoea at baseline was similar to those without diarrhoea at the end of the study (Fig. 2).

After 120 days of follow-up, children in the lower quartile (based on levels of plasma zinc) suffered a significant relative increase in the risk of days of illness by $15 \%$ (95\% confidence interval [CI] 8-22), days of diarrhoea by $22 \%$ (95\% CI 9-37), days with dysentery by $44 \%$ (95\% CI 12-135), days with ALRI by $49 \%$ (95\% CI 16-92), and pneumonia episodes by $5 \%$ (95\% CI 43-91) compared to children in the upper quartile. Risk ratios did not change after adjusting for literacy of mothers, literacy of fathers, score of socioeconomic status, source of water supply, age, and gender (Table 3).

\section{DISCUSSION}

Our study documents the epidemiology and magnitude of zinc deficiency among preschool children at the community level in an urban slum in India. It also describes the association between the levels
(17). The prevalence of zinc deficiency found in our study concurs with the results of the communitybased study carried out in Pakistan (12) and reflects the distressing magnitude and distribution of zinc deficiency. The high prevalence of zinc deficiency observed in the present study could be explained by the low bioavailability of zinc from cereal-based diets and increased rate of subclinical infection (18).

There is a lack of agreement on the normal variation in plasma zinc values according to age. Wouwe et al. found no age-dependent variation in total serum zinc among healthy Dutch infants and children (19). Likewise, Karr et al. used atomic absorption spectrophotometer to estimate the plasma zinc values in healthy preschool Australian children and found no significant age-dependent variation (20). However, the results of our study showed a higher proportion of children in the upper quartile (based on levels of plasma zinc) among the 6-11 months age-group compared to children in the higher agegroups. This could be due to appropriate breastfeeding practices among younger age-group which might lead to better zinc status.

Recent studies have shown that zinc status is influenced by consumption of test-meal among healthy adult volunteers (19). On the other hand, Bitarakwate $e t$ al. found no significant association between the nutritional status and the levels of serum zinc (21). Likewise, in our study, we observed that neither the breastfeeding status nor the consumption of zinc-rich foods, or consumption of non-breast- 


\begin{tabular}{|c|c|c|c|}
\hline \multirow[b]{2}{*}{ Variable } & \multicolumn{3}{|c|}{ Zinc quartile } \\
\hline & $\begin{array}{c}\text { Lower } 25^{*} \\
(\mathrm{n}=237)\end{array}$ & $\begin{array}{l}\text { Middle } 50^{\dagger} \\
(\mathrm{n}=476)\end{array}$ & $\begin{array}{c}\text { Upper 25‡ } \\
(\mathrm{n}=227)\end{array}$ \\
\hline \multicolumn{4}{|l|}{ Age (months) at enrollment } \\
\hline $6-11$ & $80(33.8)$ & $186(39.1)$ & $117(51.5)$ \\
\hline $12-23$ & $102(43.0)$ & $190(39.9)$ & $78(34.4)$ \\
\hline $24-35$ & $55(23.2)$ & $100(21.0)$ & $32(14.1)$ \\
\hline \multicolumn{4}{|l|}{ Nutritional status } \\
\hline Normal & $85(35.9)$ & $182(38.2)$ & $95(41.9)$ \\
\hline Wasting and stunting & $42(17.7)$ & $57(12.0)$ & $30(13.2)$ \\
\hline Wasting & $92(38.8)$ & $197(41.4)$ & $91(40.1)$ \\
\hline Stunting & $18(7.6)$ & $40(8.4)$ & $11(4.8)$ \\
\hline \multicolumn{4}{|l|}{ Breastfeeding status } \\
\hline Nil & $62(26.2)$ & $113(23.7)$ & 49 (21.6) \\
\hline Exclusive & - & $3(0.6)$ & $2(0.9)$ \\
\hline Partial & $168(70.9)$ & $345(72.5)$ & $170(74.9)$ \\
\hline Occassional & $7(3.0)$ & $15(3.2)$ & $6(2.6)$ \\
\hline \multicolumn{4}{|l|}{ Feeding during the preceding 2 weeks } \\
\hline \multicolumn{4}{|l|}{ Milk other than breastmilk feeding } \\
\hline Nil & $112(47.3)$ & $209(43.9)$ & $98(43.2)$ \\
\hline Mother dairy & $65(27.4)$ & $128(26.9)$ & $56(24.7)$ \\
\hline Polypack & $12(5.1)$ & $45(9.5)$ & $21(2.5)$ \\
\hline Powdered milk & $17(7.2)$ & $27(5.7)$ & $16(7.0)$ \\
\hline Others & $30(12.7)$ & $67(14.1)$ & $35(15.4)$ \\
\hline \multicolumn{4}{|l|}{ Frequency of zinc-rich foods } \\
\hline Age $<1$ year ${ }^{\dagger \dagger}$ & $5.4 \pm 14.9$ & $5.5 \pm 14.1$ & $4.5 \pm 12.9$ \\
\hline Age $1-2$ year(s)§ & $7.9 \pm 12.3$ & $7.1 \pm 13.7$ & $9.3 \pm 17.2$ \\
\hline Age $>2$ years & $10.2 \pm 15.9$ & $11.3 \pm 19.7$ & $10.6 \pm 16.2$ \\
\hline Diarrhoea in the last 2 months & $148(62.4)$ & $336(70.6)$ & $142(62.6)$ \\
\hline \multicolumn{4}{|l|}{$\begin{array}{l}\text { Duration (days) of diarrhoea at } \\
\text { enrollment }\end{array}$} \\
\hline$<2$ & $43(18.1)$ & $64(13.4)$ & $37(16.3)$ \\
\hline $2-4$ & $135(57.0)$ & $291(61.1)$ & $130(57.3)$ \\
\hline $5-6$ & $32(13.5)$ & $78(16.4)$ & $32(14.1)$ \\
\hline$>6$ & $27(11.4)$ & $43(9.0)$ & $28(12.3)$ \\
\hline \multicolumn{4}{|l|}{ Vomiting in the last 24 hours } \\
\hline Any & $53(22.4)$ & $78(16.4)$ & $48(21.1)$ \\
\hline$>2$ & $31(13.1)$ & $50(10.5)$ & $36(15.9)$ \\
\hline ALRI episodes in the last 2 months & $170(71.7)$ & $369(77.5)$ & $177(78.0)$ \\
\hline ALRI present & $60(25.3)$ & $54(11.4)$ & $47(20.7)$ \\
\hline SES score & $5.31 \pm 1.8$ & $5.49 \pm 1.79$ & $5.71 \pm 1.82$ \\
\hline
\end{tabular}

${ }^{*}$ Lower $25^{\text {th }}$ percentile plasma zinc $\leq 56.0 \mu \mathrm{g} / \mathrm{dL} ; \dagger$ Middle $50^{\text {th }}$ percentile $\left(\geq 25^{\text {th }}\right.$ percentile and $\leq 75^{\text {th }}$ percentile) plasma zinc $>56.0 \mu \mathrm{g} / \mathrm{dL}$ and plasma zinc $\leq 70.0 \mu \mathrm{g} / \mathrm{dL} ;$ ‡Upper $25^{\text {th }}$ percentile plasma zinc $>70.0 \mu \mathrm{g} / \mathrm{dL} ; \dagger \uparrow \mathrm{n}=80,186$, and 117 in age $<1$ year; $\S \mathrm{n}=110,199$, and 81 in age $1-2$ year(s); $\mathbb{I n}_{\mathrm{n}}=47$, 91, and 29 in age >2 years; Figures in parentheses indicate percentages; ALRI=Acute lower respiratory infection; SES=Socioeconomic status

milk during the two weeks preceding enrollment had any significant impact on the levels of plasma zinc.

Although the effects of poor intake and increased micronutrient demands are well-described, the po- tential effects of acute infections on the body's micronutrient status are less well-understood. There is little information on the short-term compartment changes of several micronutrients, including zinc following an infection (22). A recent study by Strand et al. reported a decline in concentrations 


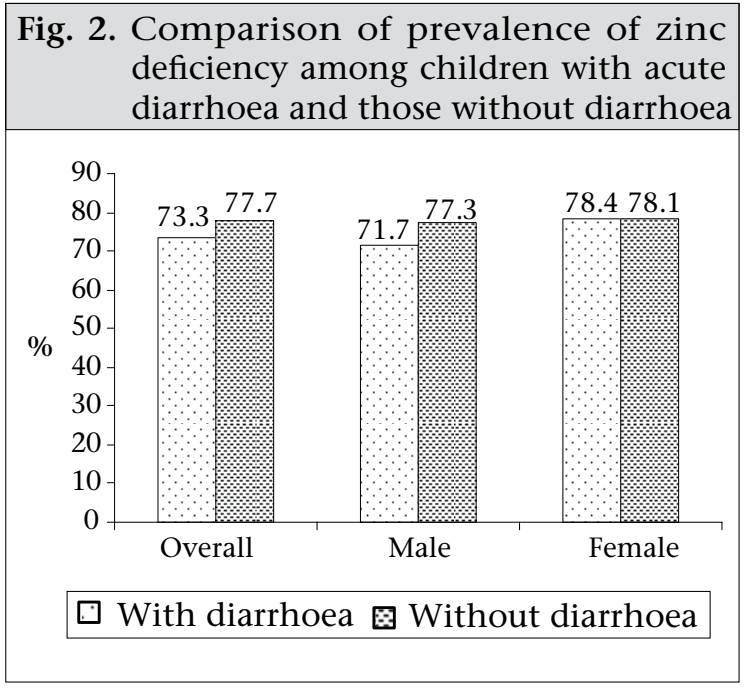

of plasma zinc during episodes of acute diarrhoea (23). Previously, Chaudhary et al. reported a significant fall in plasma zinc after acute and persistent diarrhoea in Indian children (24). Similarly, Bitarakwate et al. found that concentration of zinc stores in the body during diarrhoea to balance the loss through excretion.

There is evidence to show preventive and therapeutic effects of zinc supplementation on various childhood morbidities $(18,25-30)$. Our morbidity-related results showed that children with zinc deficiency were at a higher risk of morbidities compared to zinc-sufficient children. These results substantiate the findings of a limited number of previously-published studies conducted in similar population settings relating the zinc levels to prospective morbidities (31-32). Although our study children had acute diarrhoea at baseline, the findings are comparable as we have shown that the prevalence of zinc deficiency during diarrhoea was similar to diarrhoea-free days.

The limitations of the study include that zinc deficiency was assessed using plasma zinc only and the intake of dietary zinc was not assessed.

In conclusion, this study provides systematic information regarding the factors influencing the zinc

Table 3. Association of baseline zinc levels with prospective morbidity in 120-day follow-up comparison of lower $25^{\text {th }}$ quartile vs upper $25^{\text {th }}$ quartile

\begin{tabular}{|c|c|c|c|c|}
\hline Morbidity & Lower $25^{*}$ & Upper $25^{* *}$ & $\begin{array}{l}\text { Lower vs upper } \\
\text { RR }(95 \% \text { CI })\end{array}$ & $\begin{array}{c}\text { Adjusted RR } \dagger \\
(95 \% \mathrm{CI})\end{array}$ \\
\hline Days child ill & 0.356 & 0.311 & $\begin{array}{c}1.15 \\
(1.08-1.22)\end{array}$ & $\begin{array}{c}1.13 \\
(1.06-1.20)\end{array}$ \\
\hline Days with diarrhoea & 0.104 & 0.086 & $\begin{array}{c}1.22 \\
(1.09-1.37)\end{array}$ & $\begin{array}{c}1.32 \\
(1.18-1.49)\end{array}$ \\
\hline Episodes of diarrhoea & 0.024 & 0.024 & $\begin{array}{c}0.99 \\
(0.79-1.24)\end{array}$ & $\begin{array}{c}1.02 \\
(0.81-1.29)\end{array}$ \\
\hline Days with dysentery & 0.006 & 0.004 & $\begin{array}{c}1.44 \\
(0.88-2.35)\end{array}$ & $\begin{array}{c}1.25 \\
(0.75-2.07)\end{array}$ \\
\hline Days with ALRI & 0.026 & 0.017 & $\begin{array}{c}1.49 \\
(1.16-1.92)\end{array}$ & $\begin{array}{c}1.47 \\
(1.14-1.90)\end{array}$ \\
\hline No. of pneumonia episodes & 0.003 & 0.003 & $\begin{array}{c}1.05 \\
(0.57-1.91)\end{array}$ & $\begin{array}{c}1.04 \\
(0.56-1.94)\end{array}$ \\
\hline
\end{tabular}

in serum of children with persistent diarrhoea was significantly lower than that of children without diarrhoea (21). However, our results showed that the prevalence of zinc deficiency (plasma zinc $<70.0$ $\mu \mathrm{g} / \mathrm{dL}$ ) at baseline when all the children had acute diarrhoea was comparable with the prevalence in the second sample among the children who did not have diarrhoea three days before the last bloodsampling. This could be due to the homeostatic control mechanism in the body that shifts zinc levels among preschool children in low socioeconomic settings and substantiates the relationship between zinc levels and prospective morbidities.

\section{AKNOWLEDGEMENTS}

The authors acknowledge the contributions of parents of the study children, study team, including health workers, supervisors, physicians, technicians, data management, and other support staff. The authors also acknowledge contributions 
of the World Health Organization and the Thrasher Research Fund for funding the study.

\section{REFERENCES}

1. Black RE. Zinc deficiency, infectious disease and mortality in the developing world. J Nutr 2003;133(Suppl 1):1485S-9S.

2. Bhandari N, Bahl R, Taneja S, Strand T, Mølbak K, Ulvik RJ et al. Substantial reduction in severe diarrheal morbidity by daily zinc supplementation in young north Indian children. Pediatrics 2002;109:e86.

3. Bhutta ZA, Black RE, Brown KH, Gardner JM, Gore S, Hidayat A et al. Prevention of diarrhea and pneumonia by zinc supplementation in children in developing countries: pooled analysis of randomized controlled trials. Zinc Investigators' Collaborative Group. J Pediatr 1999;135:689-97.

4. Gibson RS. Zinc: a critical nutrient in growth and development. N Z Med J 1998;111:63-4.

5. Sazawal S, Black RE, Menon VP, Dinghra P, Caulfield LE, Dhingra U et al. Zinc supplementation in infants born small for gestational age reduces mortality: a prospective, randomized, controlled trial. Pediatrics 2001;108:1280-6.

6. de Benoist B, Darnton-Hill I, Davidsson L, Fontaine $\mathrm{O}$, Hotz C. Conclusions of the Joint WHO/UNICEF/ IAEA/IZiNCG Interagency Meeting on Zinc Status Indicators. Food Nutr Bull 2007;28(Suppl):S480-4.

7. Vijayaraghavan K. Control of micronutrient deficiencies in India: obstacles and strategies. Nutr Rev 2002;60:S73-S76.

8. Hotz C, Lowe NM, Araya M, Brown KH. Assessment of the trace element status of individuals and populations: the example of zinc and copper. J Nutr 2003;133(Suppl 1):1563S-8S.

9. Serra-Majem L. Food availability and consumption at national, household and individual levels: implications for food-based dietary guidelines development. Public Health Nutr 2001;4:673-6.

10. Wuehler S, Peerson J, Brown K. Estimation of the global prevalence of zinc deficiency using national food balance data (abstract). FASEB J 2000;14:A510. (http://wwwzinc-health org/Health/Ab-s1p-ws cfm 2005, accessed on 15 February 2005).

11. International Zinc Nutrition Consultative Group. Assessment of the risk of zinc deficiency in populations and options for its control. Editors: C Hotz, $\mathrm{KH}$ Brown. Food Nutr Bull 2004;25:S94-203.

12. Paracha Pi JA. Prevalence of zinc deficiency and subclinical infection in Pakistani pre-school children. (http://wwwzinc-health org/Health/Ab-s1-pp cfm, accessed on 15 February 2005).
13. Bhan MK, Sommerfelt $H$, Strand T. Micronutrient deficiency in children. Br J Nutr 2001;85:S199-S203.

14. Sazawal S, Black RE, Bhan MK, Bhandari N, Sinha A, Jalla S. Zinc supplementation in young children with acute diarrhea in India. N Engl J Med 1995;333:83944.

15. Sazawal S, Black RE, Bhan MK, Jalla S, Bhandari N, Sinha A et al. Zinc supplementation reduces the incidence of persistent diarrhea and dysentery among low socioeconomic children in India. J Nutr 1996;126:44350.

16. Hambidge KM, King JC, Kern DL, English-Westcott JL, Stall C. Pre-breakfast plasma zinc concentrations: the effect of previous meals. J Trace Elem Electrolytes Health Dis 1990;4:229-31.

17. Sandstead HH. Zinc deficiency. A public health problem? Am J Dis Child 1991;145:853-9.

18. Bhandari N, Bahl R, Taneja S, Strand T, Mølbak K, Ulvik RJ et al. Substantial reduction in severe diarrheal morbidity by daily zinc supplementation in young north Indian children. Pediatrics 2002;109:e86.

19. Van Wouwe JP, Waser I. Comparison between total and ultrafiltrable serum zinc as test to diagnose zinc deficiency in infants and children. Biol Trace Elem Res 1994;40:203-11.

20. Karr M, Mira M, Causer J, Earl J, Alperstein G, Wood F et al. Plasma and serum micronutrient concentrations in preschool children. Acta Paediatr 1997;86:677-82.

21. Bitarakwate E, Mworozi E, Kekitiinwa A. Serum zinc status of children with persistent diarrhoea admitted to the diarrhoea management unit of Mulago Hospital, Uganda. Afr Health Sci 2003;3:54-60.

22. Bhutta ZA. Effect of infections and environmental factors on growth and nutritional status in developing countries. J Pediatr Gastroenterol Nutr 2006;43:S13S21.

23. Strand TA, Adhikari RK, Chandyo RK, Sharma PR, Sommerfelt H. Predictors of plasma zinc concentrations in children with acute diarrhea. Am J Clin Nutr 2004;79:451-6.

24. Chaudhary S, Verma M, Dhawan V, Nain CK, Kumar R, Kumar L et al. Plasma vitamin A, zinc and selenium concentrations in children with acute and persistent diarrhoea. J Diarrhoeal Dis Res 1996;14:190-3.

25. Black RE. Therapeutic and preventive effects of zinc on serious childhood infectious diseases in developing countries. Am J Clin Nutr 1998;68:476S-9S.

26. Osendarp SJ, Santosham M, Black RE, Wahed MA, van Raaij JM, Fuchs GJ. Effect of zinc supplementation between 1 and 6 mo of life on growth and morbidity of Bangladeshi infants in urban slums. Am J Clin Nutr 2002;76:1401-8. 
27. Penny ME, Marin RM, Duran A, Peerson JM, Lanata CF, Lönnerdal B et al. Randomized controlled trial of the effect of daily supplementation with zinc or multiple micronutrients on the morbidity, growth, and micronutrient status of young Peruvian children. Am J Clin Nutr 2004;79:457-65.

28. Roy SK, Tomkins AM, Haider R, Behren RH, Akramuzzaman SM, Mahalanabis D et al. Impact of zinc supplementation on subsequent growth and morbidity in Bangladeshi children with acute diarrhoea. Eur J Clin Nutr 1999;53:529-34.

29. Sazawal S, Black RE, Bhan MK, Bhandari N, Sinha A, Jalla S. Zinc supplementation in young children with acute diarrhea in India. N Engl J Med 1995;333:83944.
30. Sazawal S, Black RE, Bhan MK, Jalla S, Bhandari N, Sinha A et al. Zinc supplementation reduces the incidence of persistent diarrhea and dysentery among low socioeconomic children in India. $J$ Nutr 1996;126:443-50.

31. Bahl R, Bhandari N, Hambidge KM, Bhan MK. Plasma zinc as a predictor of diarrhea and respiratory morbidity in children in a urban slum setting. Am J Clin Nutr 1998;68:414S-7S.

32. Ece A, Uyanik BS, Işcan A, Ertan P, Yiğitoğlu MR. Increased serum copper and decreased serum zinc levels in children with iron deficiency anemia. Biol Trace Elem Res 1997 Winter;59:31-9. 